\title{
Total Synthesis of (+)-Hosieine A
}

\section{Key words}

\section{(+)-hosieine A}

Rautenstrauch rearrangement

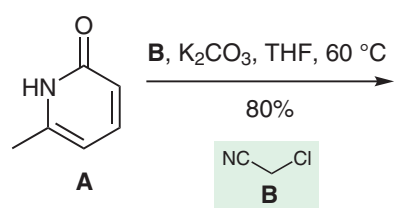<smiles>Cc1cccc(=O)n1CC#N</smiles>

1. D, $\mathrm{AlCl}_{3}(40 \mathrm{~mol} \%), \mathrm{THF},-78^{\circ} \mathrm{C}$ 2. $\mathrm{E}, \mathrm{CeCl}_{3}, \mathrm{THF},-78^{\circ} \mathrm{C}$

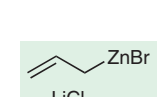

$87 \%$

LiCl D

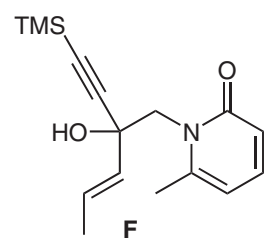

E $\mathrm{F}$

1. LDA, G, THF, $-78^{\circ} \mathrm{C}$ then PivCl, $-78^{\circ} \mathrm{C}$

2. $\mathrm{MeOH}, \mathrm{K}_{2} \mathrm{CO}_{3}$

$90 \%$
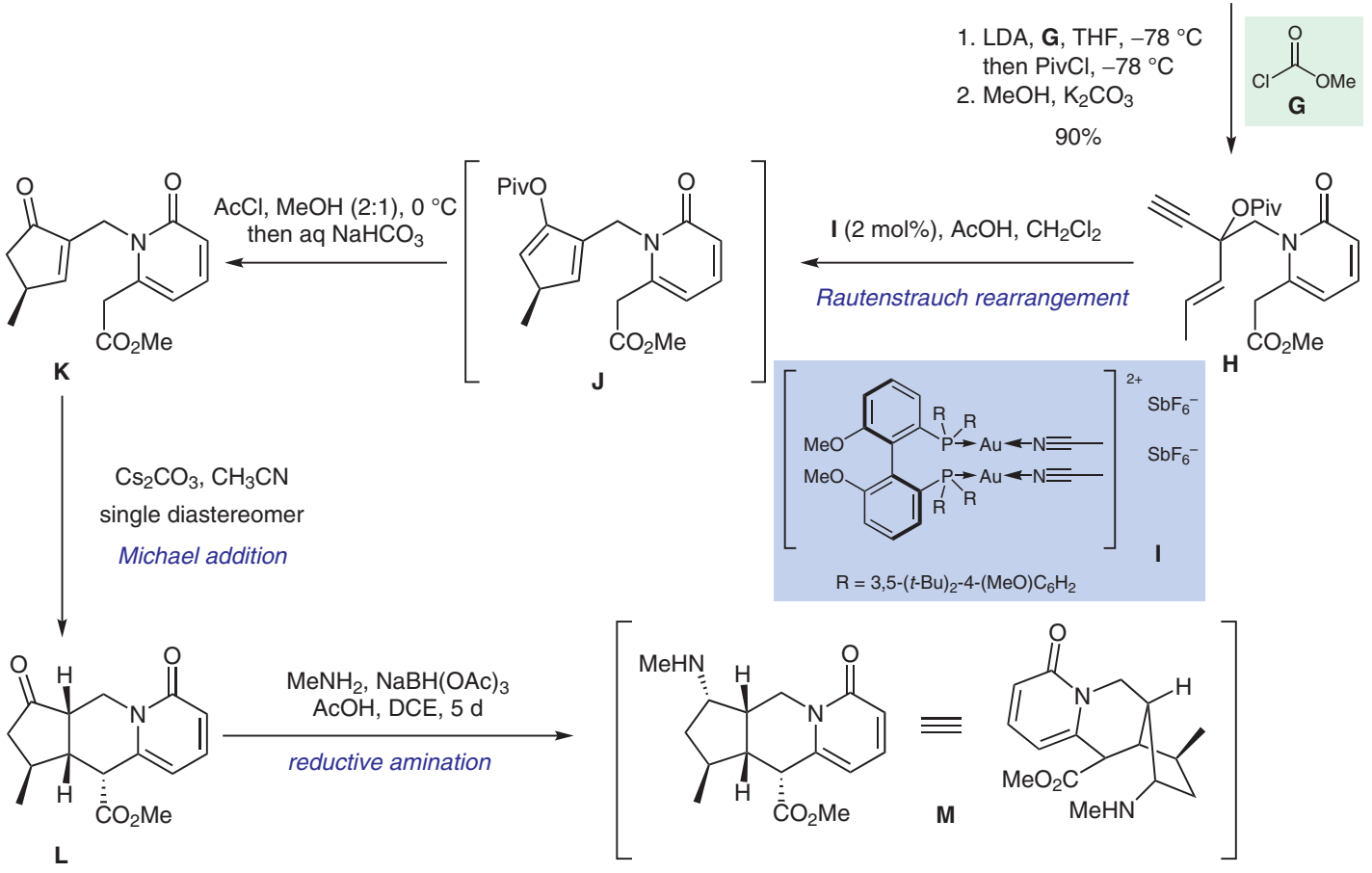

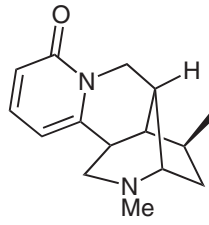

(+)-hosieine A

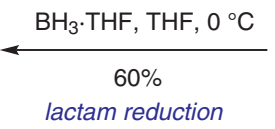

lactam reduction lactam reduction

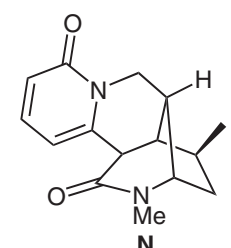

N
$80 \%$ ee

$42 \%$ from $\mathbf{H}$ lactamization enantioconvergent gold catalysis

Michael addition

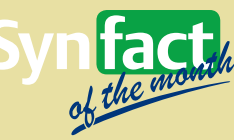

Significance: The authors report a nine-step total synthesis of enantioenriched (+)-hosieine A. Natural products of the hosieine family were isolated from $O$. hosiei and show nanomolar activity against the nicotinic acetylcholine receptors (nAChRs). For a previous synthesis of (-)-hosieine A, see: J. Ouyang, R. Yan, X. Mi, R. Hong Angew. Chem. Int. Ed. 2015, 54, 10940.
Comment: The synthesis relied on a goldcatalyzed, enantioconvergent Rautenstrauch rearrangement that afforded enone $\mathbf{K}$. After baseinduced Michael addition to form $\mathbf{L}$ and reductive amination, spontaneous lactamization took place to give $\mathbf{N}$. The lactam was reduced eventually with borane to give enantioenriched (+)-hosieine A.

SYNFACTS Contributors: Erick M. Carreira, Felix Pultar

Synfacts 2018, 14(08), 0777 Published online: 18.07.2018 Dol: 10.1055/s-0037-1609882; Reg-No.: C03618SF 